\title{
Microcutting and Hollow 3D Microstructures in Glasses by In-volume Selective Laser-induced Etching (ISLE)
}

\author{
Jens GOTTMANN, Martin HERMANS, Jürgen ORTMANN \\ Lehrstuhl für Lasertechnik, RWTH Aachen University, Steinbachstr. 15, 52074 Aachen, Germany
}

\begin{abstract}
3D microfluidic devices and assembled micro mechanics inside fused silica glass are produced directly from digital $\mathrm{CAD}$ data e.g. for markets like medical diagnostics. To exploit the potential productivity of new high average power fs-lasers $(150 \mathrm{~W}-1 \mathrm{~kW})$ a modular high speed scanning system has been developed. Acousto-optical beam deflection, galvo-scanners and translation stages are controlled by CAM software. Using a lens with $10 \mathrm{~mm}$ focal length a focus radius of $1 \mu \mathrm{m}$ is scanned with a velocity of $12 \mathrm{~m} / \mathrm{s}$ on $400 \mu \mathrm{m}$ track radius enabling the up-scaling of the ISLEprocess using large repetition rate and large average power.
\end{abstract}

DOI:10.2961/jlmn.2013.01.0004

Keywords: In-volume selective laser-induced etching, microchannel, microstructuring in glass, high speed microscanner, digital photonic production

\section{Introduction}

Microfluidic devices for applications e.g. in medical diagnostics benefit from chemically inert transparent materials like glass or sapphire. 3D micro structuring enables new designs of complex integrated microfluidics or assembled micromechanics. In-volume selective laser-induced etching (ISLE) of microchannels in fused silica glass and sapphire is a fabrication process under investigation for more than eight years now [1-6]. Since special micro-scanners with CAM software [7] have been developed and versatile tabletop machining centers are in development [8], 3D digital production of complex micro structured parts is possible using ISLE [9]. However since traditional focus scanning using translation stages and galvo-scanners are only able to exploit the productivity of low average power fs-fiber lasers $(<5 \mathrm{~W})$ the recent development of high average power fs-slab amplifiers $(150 \mathrm{~W}-1 \mathrm{~kW})$ makes the development of fast laser scanning necessary. Therefore, the development of a high speed micro-scanner is the challenge to enable fast digital photonic production of microstructured transparent devices.

\section{Experimental}

In-volume selective laser-induced etching (ISLE) is a two-step process: In the first step material transparent to the laser radiation is modified locally inside the volume. For this purpose ultrashort laser radiation $(\lambda=1030 \mathrm{~nm}$, repetition rate $0.5-27 \mathrm{MHz})$ from an fs-fiber laser $(\mathrm{P}=5 \mathrm{~W})$ amplified by a slab-amplifier $(\mathrm{P}=150 \mathrm{~W}$, repetition rate 5$27 \mathrm{MHz}$ ) is focused inside the glass material with a numerical aperture of 0.3 . In the focus volume the intensity of the laser radiation is large enough to enable the absorption by multi-photon processes because the material is transparent at lower intensities. A connected volume inside the material is modified by scanning of repetitive pulses, which must have at least one contact to the surface of the work piece. For digital production of 3D microstructures from the CAD data a set of stacked 2D scanning trajectories are computed (slicing; Fig. 1 left), which are fed subsequently from bot- tom to top to the CAM software controlling the translation stages, the modules of the scanning system and the laser power synchronously. If the structure to be produced is larger than the scanning field of the lens, the 2D trajectories are divided in adjacent tiles by the CAM software and are scanned and stepped subsequently (Fig. 1 center).

In the second step the work piece is exposed to aqueous solution of potassium hydroxide (KOH) [10] for $48 \mathrm{~h}$ in an ultrasonic bath. Because the material, modified by the laser radiation, is etched much faster than the unmodified material, the modified volume is selectively removed resulting in hollow structures inside the work piece. The selectivity, that is the ratio of the etching rate of the modified material to the etching rate of the unmodified material, can be as high as 1,000. After etching, the microstructures are cleaned with water and ethanol and characterized using optical microscopy (Fig. 1 right, Fig. 7).
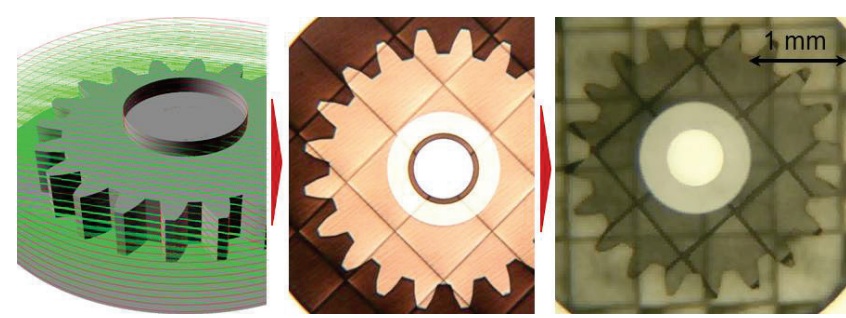

Fig. 1 Laser trajectories generated from 3D CAD file (schematic, left), micrograph of modified structure (center) and resulting microstructure after etching (right)

\section{Results}

\subsection{High Speed Microscanner}

For rapid digital production of 3D microstructures parts with $1 \mu \mathrm{m}$ precision utilizing high average power fs-lasers $(\mathrm{P}=150 \mathrm{~W})$ a modular scanning system has been developed. Modular combinations of acousto-optical beam deflection, galvo scanner and translation stages have been set-up as a prototype called LightFab (Fig. 2), which can be equipped 
with various focusing optics. For example using a telecentric lens with $10 \mathrm{~mm}$ focal length a focus radius of $\omega_{0}=1$ $\mu \mathrm{m}$ is scanned with a velocity of $\mathrm{v}=12 \mathrm{~m} / \mathrm{s}$ on a $400 \mu \mathrm{m}$ track radius. Therefore, spatial separation of laser pulses (without spatial overlap of the pulses) is possible at laser repetition rates as high as $\mathrm{f}=5 \mathrm{MHz}$.

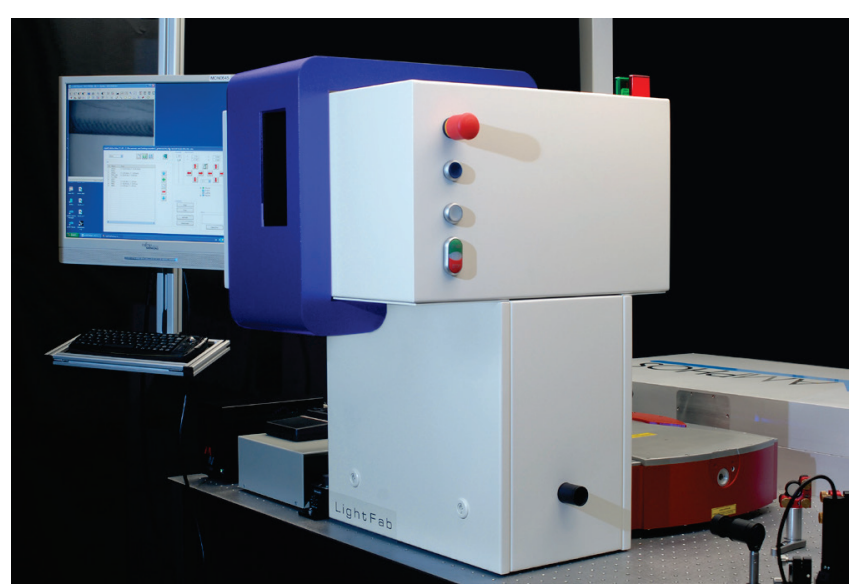

Fig. 2 Modular high speed micro scanner system LightFab

\subsection{Absorptivity}

Since the absorptivity of glasses depends on processing variables such as repetition rate, velocity and the applied pulse energy it is measured during modification to determine the absorbed power [11]. Using the borosilicate glass D263 the absorptivity increases with increasing repetition rate and pulse energy from $0 \%$ to $>60 \%$ (Fig. 3). Increasing the velocity from $1 \mathrm{~mm} / \mathrm{s}$ to $200 \mathrm{~mm} / \mathrm{s}$ is resulting in a decrease of the absorptivity of $\sim 10 \%$ in average. Using a laser power $>0.5-2 \mathrm{~W}$ more than $50 \%$ of the laser power are absorbed in the material and the absorption is dominated by linear absorption processes like absorption by thermally excited electrons in the volume heated by heat accumulation of multiple pulses [12]. Therefore, a further increase of repetition rate, laser power and scanning velocity is considered to result in an almost linear increase of productivity of the laser modification process.

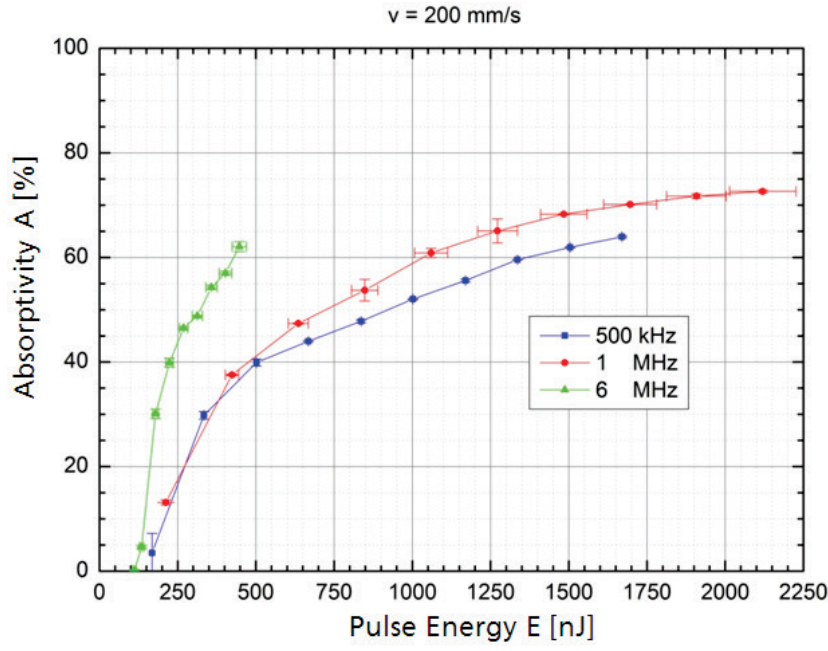

Fig. 3 Absorptivity measured in D263 during modification with $0.5-6 \mathrm{MHz}$ repetition rate and scanning velocity of $200 \mathrm{~mm} / \mathrm{s}$

\subsection{D Microfluidic Device}

A 3D micro fluidic device for medical diagnostics has been produced by ISLE in $2 \mathrm{~mm}$ thick fused silica. The microstructure consists of a tapered buried flat microchannel for microscopic diagnosis and two cylindrical inlet pipes each equipped with connectors for flexible tubes (Fig. 4).

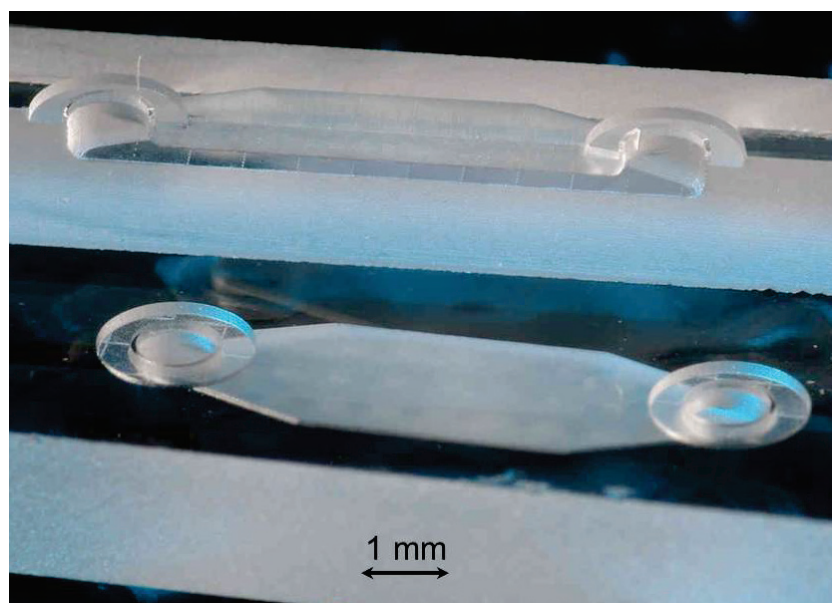

Fig. 4 3D micro fluidic device in $2 \mathrm{~mm}$ thick fused silica made by ISLE directly from CAD file (top-view and cross-section) in fused silica

To investigate the up-scaling of the ISLE process a straight micro channel with a cross-sectional area of $50 \times 630 \mu \mathrm{m}$ has been produced in fused silica by scanning the laser focus $\omega_{0}=1 \mu \mathrm{m}$ on a circle of $630 \mu \mathrm{m}$ diameter with a velocity of $\mathrm{v}=10 \mathrm{~m} / \mathrm{s}$ and simultaneously translating the sample with (Fig. 5). Using pulse duration of $500 \mathrm{fs}$, a repetition rate of $27 \mathrm{MHz}$ and a laser power of $16.2 \mathrm{~W}$ the ISLE process is possible without visible cracks after etching (Fig. 5, top). Increasing the power to $>24 \mathrm{~W}$ results in microchannels with visible cracks (Fig. 5, center). Using pulse duration of 5 ps by stretching the laser radiation, a laser power of $>24 \mathrm{~W}$ is necessary to initiate the ISLE process resulting in microchannels with already visible cracks (Fig. 5, bottom).

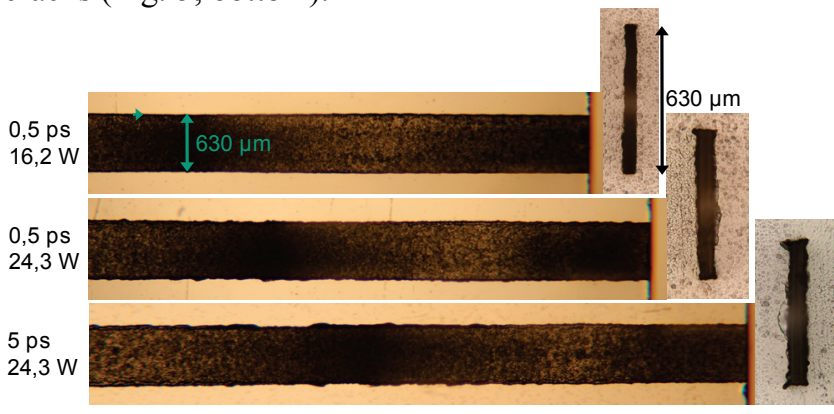

Fig. 5 Micro channel $8 \mathrm{~mm}$ long and $630 \mu \mathrm{m}$ wide (top view, left) and cross-section 50-80 $\mu \mathrm{m} \times 630 \mu \mathrm{m}$ (right) in fused silica

\subsection{Assembled micro mechanics and microcutting of holes in fused silica}

Further demonstrations of applications of ISLE with the use of high speed scanning include the production of a $50 \times 50$ field of holes with a diameter of $73 \mu \mathrm{m}$ (Fig. 7). A tolerance of the holes' diameter of $\pm 1 \mu \mathrm{m}$ has been obtained by microcutting the $1 \mathrm{~mm}$ thick fused silica: The surface area of a cylinder has been modified by helical 
scanning of the laser focus and after etching the cut-out glass cylinders are removed. Using an average laser power $<4 \mathrm{~W}$ the processing time is $<1 \mathrm{~s}$ per hole. Further upscaling of the productivity is planned using high power laser radiation.

To demonstrate the fabrication of assembled micromechanics by digital photonic production from 3D-CAD data using ISLE in fused silica a gear has been produced already mounted on its axis (Fig 1). The gear has a diameter of 3 $\mathrm{mm}$ and a thickness of $500 \mu \mathrm{m}$ and after the etching step it is able to rotate freely on its axis $600 \mu \mathrm{m}$ in diameter (Fig. $8)$. Due to limited selectivity of the etching process the minimal gap width is $\sim 10 \mu \mathrm{m}$ and the minimal gap height is $\sim 20 \mu \mathrm{m}$ and a surface roughness $\mathrm{R}_{\mathrm{Z}} \sim 1 \mu \mathrm{m}$ are obtained while a precision of $2 \mu \mathrm{m}$ is possible after taking the tapering due to etching into account.

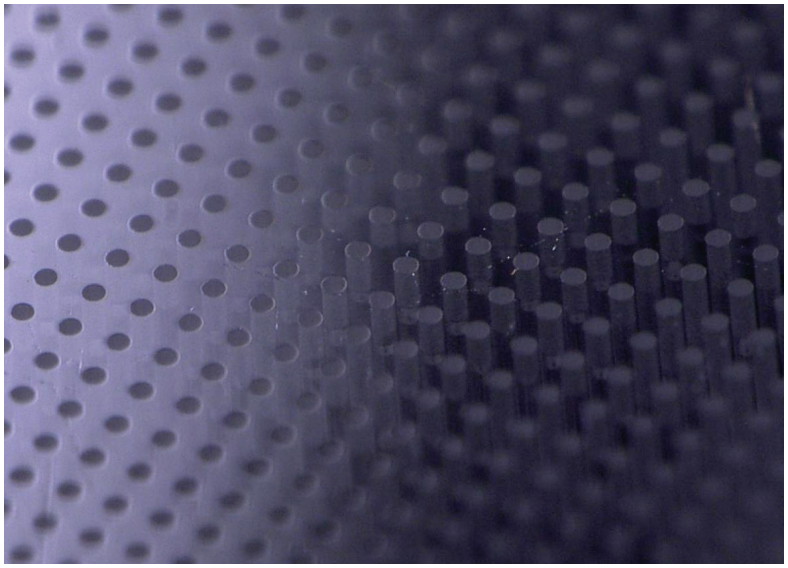

Fig. 7 Holes with $73 \mu \mathrm{m}$ diameter made by cutting $1 \mathrm{~mm}$ thick fused silica glass using ISLE
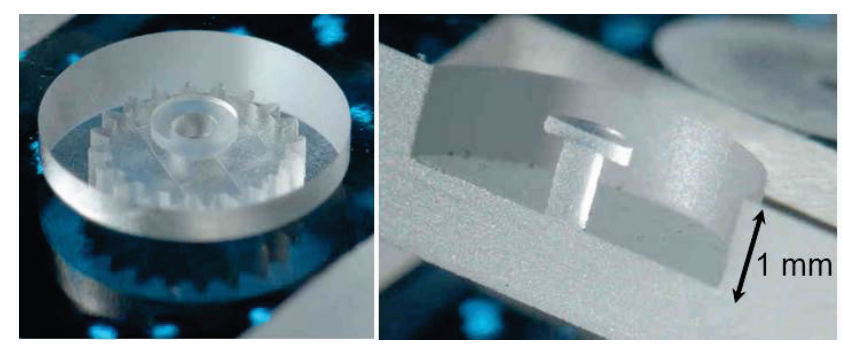

Fig. 8 Free rotating gear (left) produced directly from CAD data already assembled on its shaft (cross-section, right) by ISLE

\section{Summary and Outlook}

Using In-volume selective laserinduced etching (ISLE) digital photonic production of microfluidic devices and already assembled micromechanical parts has been demonstrated directly from the 3D CAD data.

To utilize high average power fs-lasers $(\mathrm{P}=150 \mathrm{~W})$ a modular high speed scanning system has been developed. By combination of acousto-optical beam deflection, galvo scanner and translation stages using a lens with $10 \mathrm{~mm}$ focal length a focus radius of $\omega_{0}=1 \mu \mathrm{m}$ has been scanned with a velocity of $\mathrm{v}=12 \mathrm{~m} / \mathrm{s}$ on a $400 \mu \mathrm{m}$ track radius.

The scaling of the ISLE process to high power $(30 \mathrm{~W})$ and high velocity $(10 \mathrm{~m} / \mathrm{s})$ has been demonstrated by fabri- cation of $8 \mathrm{~mm}$ long microchannels in fused silica free of visible cracks using fs-laser radiation. Using ps-laser radiation up to now the fabricated microchannels are not free of cracks. Further process optimization is needed to clarify, whether a processing window exist for the fabrication of crack-free microchannels using ps-laser radiation for ISLE.

Both the microstructured parts made by ISLE and the high speed microscanner will soon be made commercially available via a spin-off by the authors.

\section{Acknowledgments}

(1) The work on the high speed micro scanner project is funded by NRW.Transfer Science-to-Business PreSeed to prepare the spin-off.

(2) The authors are gratefull to IMRA America inc. for the possibility to use the $\mu$ Jewel laser in the Premier Applications Lab at LLT.

\section{References}

[1] Y. Bellouard, A. Said, M. Dugan, P. Bado: "Fabrication of high-aspect ratio micro fluidic channels and tunnels using femtosecond laser pulses and chemical etching", Optics Express, 12, (2004), 2120

[2] C. Hnatovsky, R. S. Taylor, E. Simova, V. R. Bhardwaj, D. M. Rayner, P. B. Corkum: "Polarizationselective etching in femtosecond laser-assisted microfluidic channel fabrication in fused silica", Optics Letters, 30, (2005), 1867-1869

[3] S. Matsuo, Y. Shickijo, T. Tomita, S. Hashimoto: "Laser fabrication of ship-in-a-bottle microstructures in sapphire", JLMN, 2, (2007), 114-116

[4] D. Wortmann, J. Gottmann, N. Brandt, H. Horn-Solle: "Micro- and nanostructures inside sapphire by fs-laser irradiation and selective etching", Optics Express, 16, (2008), 1517-1522

[5] R. Osellame, H.J.W.M. Hoekstra, G. Cerullo, M. Pollnau: "Femtosecond laser microstructuring: an enabling tool for optofluidic lab-on-chips", Laser Photonics Rev., 5, (2011), 442-463

[6] Y. Liao, J. Song, E. Li, Y. Luo, Y. Shen, D. Chen, Y. Chen, Z. Xu, K. Sugioka, K. Midorikawa: "Rapid prototyping of three-dimensional microfluidic mixers in glass by femtosecond laser direct writing", Lab on a Chip, 12, (2012), 746-749

[7] J. Gottmann, M. Hörstmann-Jungemann, M. Hermans, D. Beckmann: "High speed and high precision fs-laser writing using a scanner with large numerical aperture", JLMN, 4, (2009), 192-196

[8] Y. Bellouard, A. Champion, B. Lenssen, M. Matteucci, A. Schaap, M. Beresna et. al.: "The femtoprint project", JLMN, 7, (2012), 1-10

[9] J. Gottmann, M. Hermans, M. Hörstmann-Jungemann, D. Schaefer: "Selective laser etching of sapphire and glasses", Industrial Laser Solutions, 2, (2012), 8-13

[10]S. Kiyama, S. Matsuo, S. Hashimoto, Y. Morihira: "Examination of etching agent and etching mechanism on femtosecond laser microfabrication of channels inside vitreous silica substrates", J. Phys. Chem. C, 113, (2009), 11560-11566

[11] M. Hermans, J. Gottmann, A. Schiffer: "In-situ diagnostics on fs-laser-induced modifications of glasses for selective etching", Proc. SPIE, 8244, (2012), 82440E 
[12]I. Miyamoto, K. Cvecek, M. Schmidt: "Evaluation of nonlinear absorptivity in internal modification of bulk glass by ultrashort laser pulses", Optics Express, 19, (2011), 10714-10727

(Received: June 29, 2012, Accepted: November 11, 2012) 